Ying Zhou*, Xiao-Min Chen and Shengfeng Qin

\title{
A Strain-Compensated Constitutive Model for Describing the Hot Compressive Deformation Behaviors of an Aged Inconel 718 Superalloy
}

https://doi.org/10.1515/htmp-2018-0108

Received June 30, 2018; accepted September 18, 2018

\begin{abstract}
The hot deformation behaviors of an aged Inconel 718 superalloy are investigated by isothermal compression experiments at four strain rates and five deformation temperatures on a Gleeble-3500 thermo-mechanical simulator. The experimental results show that the true stresses are obviously affected by strain rate and deformation temperature. The true stress increases rapidly at the beginning of hot compressive deformation, which ascribes to the intense work hardening. The true stresses at high deformation temperatures are lower than those at lower deformation temperatures. The dynamic softening induced by DRX is weak at a relatively low deformation temperature. A strain-compensated Arrhenius-type constitutive equation linked with true stress, strain rate and deformation temperature is developed for the studied superalloy. The material constants $(\alpha, n, Q$ and $A)$ in the developed model are expressed as the functions of true strain. The flow stresses calculated by the developed constitutive equation are nicely consistent with the experimental ones, which confirms that the developed constitutive equation can accurately describe the hot deformation behaviors of the studied superalloy.
\end{abstract}

Keywords: alloy, constitutive equation, hot deformation, flow stress

\section{Introduction}

Deformation behaviors of alloys in high temperature forming processes (hot rolling, forging and extrusion) are often complicated, and difficult to accurately describe [1]. It is

*Corresponding author: Ying Zhou, School of Mechanical and Electrical Engineering, Central South University, Changsha 410083, China, E-mail: zhouying@csu.edu.cn; 28801856@qq.com Xiao-Min Chen, School of Mechanical and Electrical Engineering, Central South University, Changsha 410083, China; College of Automobile and Mechanical Engineering, Changsha University of Science and Technology, Changsha 410114, China

Shengfeng Qin, School of Design, Northumbria University, Newcastle upon Tyne NE1 2SW, UK recognized that the deformation temperature and strain rate play huge impacts on the mechanisms of work hardening, as well as dynamic softening induced by dynamic recrystallization (DRX) [2-5] or dynamic recovery (DRV) [6-10]. The constitutive models link with flow stress, temperature and the strain rate, mathematically represents the flow properties of alloys. Generally, it is necessary to establish suitable constitutive model to analyze deformation responses of alloys under specific load conditions [1, $6,11]$. To accurately describe the hot deformation behaviors of alloys, a great number of researchers have focused on the development of constitutive models [1, 12]. Lin et al. [13] developed a strain-compensated Arrhenius-type constitutive equation to describe relationship between flow stress and deformation parameters (deformation temperature and strain rate) for a $42 \mathrm{CrMo}$ steel. Also, similar constitutive models were established to describe the flow behaviors of various alloys [5, 14-17]. Compared with other models such as Zerilli-Armstrong, the stain-compensated Arrhenius-type constitutive model can more accurately describe the flow behavior of alloys $[1,13]$. Recent researches combine with some typical intelligent method such as artificial neural network (ANN), support vector regression model, and deep belief networks, which are also popular in predicting deformation behavior [8, 18-21].

Inconel 718 superalloy, as a typical nickel-base superalloy, is extensively applied in aerospace and energy industries, due to its superior mechanical properties. Moreover, its good workability makes forging and welding easy [22-27]. For Inconel 718 superalloy, Arrhenius-type constitutive equations were also used to describe hot deformation behaviors [16, 28]. Azarbarmas et al. [29] improved Arrhenius-type equation by multivariable regression. Lin et al. [29] developed the constitutive formulas for Inconel 718 superalloy to characterize the high-temperature deformation behavior at both dynamic softening and work hardening stages.

Although, some constitutive models have been developed to describe the hot deformation behaviors of superalloys, the further investigations on the hot compressive deformation behavior are still needed to optimize the hot 
forming parameters. In this study, isothermal compression tests are conducted to investigate the hot deformation behavior of an aged Inconel 718 superalloy. A strain-compensated Arrhenius-type constitutive model is established to predict the flow stress. In addition, the error analysis for the established constitutive equation is also analyzed.

\section{Materials and experiments}

A commercial Inconel 718 superalloy was employed in this study. Its chemical compositions (wt. \%) were shown in Table 1. Cylinder specimens with size of $\Phi 8 \mathrm{~mm} \times 12 \mathrm{~mm}$ were cut from the forged billet. Before the compression, the samples were solution-treated for $45 \mathrm{~min}$ at $1,040{ }^{\circ} \mathrm{C}$, and then quenched by water. Afterwards, the solution-treated samples were aged at $900{ }^{\circ} \mathrm{C}$ for $6 \mathrm{~h}$, followed by water quenching. Isothermal compression experiments were carried out on a Gleeble-3500 thermal mechanical simulator. Four strain rates $\left(0.001,0.01,0.1\right.$, and $\left.1 \mathrm{~s}^{-1}\right)$ and five deformation temperatures $\left(920^{\circ} \mathrm{C}, 950{ }^{\circ} \mathrm{C}, 980^{\circ} \mathrm{C}, 1,010^{\circ} \mathrm{C}\right.$, and $1,040{ }^{\circ} \mathrm{C}$ ) were chosen according to the industry forming process of the studied superalloy. The deformation degree (height reduction of the initial samples) was $60 \%$ height of the initial samples. Prior to the hot compressive deformation, the specimens were heated to the designed deformation temperature a rate of $10^{\circ} \mathrm{C} / \mathrm{s}$, and maintained for $300 \mathrm{~s}$ to ensure the uniform temperature distribution. Thin tantalum foil $(0.1 \mathrm{~mm})$ was placed between the specimen and dies to reduce the friction and avoid the adhesion. The true stress and strain were automatically obtained by the test system.

\section{Results and discussion}

\section{Flow characteristics}

Figure 1 shows the relationship between the true stress and true strain. Clearly, it indicates that the true stresses are susceptible to the deformation temperature and strain rate. The true stress increases rapidly at the beginning of deformation. Afterwards, it progressively decreases until a fairly steady state appears. The feature of the true stress-strain curves can be ascribed to the intense competition between the work hardening and dynamic softening (caused by DRV and DRX) mechanisms [3, 4, 7, 30]. At the incipient deformation stage, the multiplication and accumulation of dislocation stimulate the intense work hardening in the deformed block. However, the dynamic recovery induced by dislocation climb and cross-slip is too weak to neutralize the work hardening [7, 10, 12, 31]. Thus, the true stress rapidly rises with the increase of true strain. Once the accumulated dislocation density exceeds the critical strain for DRX, the nucleation and growth of DRX grains proceed, which cause the annihilation and rearrangement of dislocation, and the work hardening is weaken. Especially, DRX plays the dominant role on

Table 1: The chemical composition of the studied Inconel 718 superalloy (wt. \%).

\begin{tabular}{lrrrrrrrrr}
\hline Compositions & Ni & Cr & Nb & Mo & Ti & Al & Co & C & Fe \\
\hline Content (wt. \%) & 52.80 & 18.96 & 5.23 & 3.01 & 1.00 & 0.59 & 0.01 & 0.03 & Bal. \\
\hline
\end{tabular}

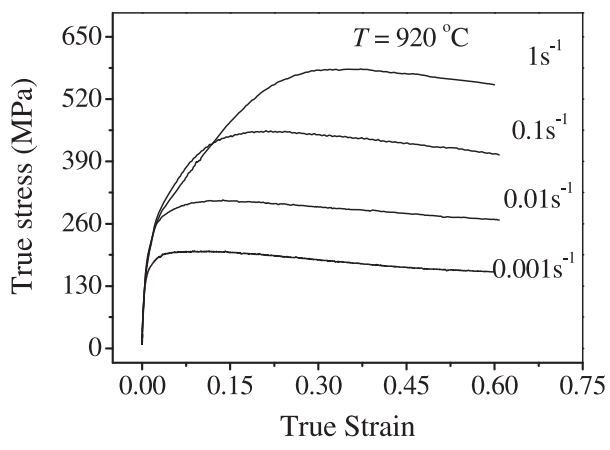

(a)

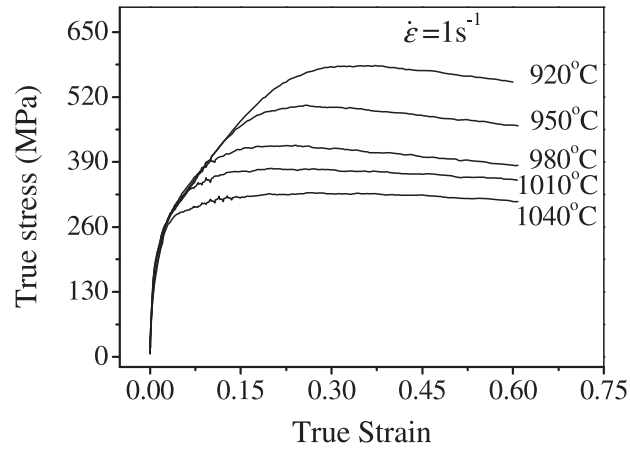

(b)

Figure 1: Typical illustrated true stress-strain curves of the studied superalloy at: (a) $T=920{ }^{\circ} \mathrm{C}$ and (b) $\dot{\varepsilon}=1 \mathrm{~s}^{-1}$. 
dynamic softening after the peak stress [21, 24, 32]. Therefore, the true stress is continuously decreased. At a relatively large strain, the true stress keeps an almost steady state, which is attributed to a new balance between the work hardening and dynamic softening. From Figure 1a, it is noteworthy that the true stress increases as the strain rate is raised at a fixed deformation temperature. The reason is that high dislocation density caused by work hardening at high strain rates can lead to the large deformation resistance [33]. In the meantime, as shown in Figure 1b, the true stresses at high deformation temperatures are lower than those at lower deformation temperatures. This is because low deformation temperature hinders the grain boundary mobility, as well as the nucleation and growth of dynamic recrystallization [34]. So, the softening induced by DRX is weak at a relatively low deformation temperature $[7,35]$.

\section{Determination of the material constants}

Arrhenius-type equation is usually applied to depict the inner connection of true stress, strain rate and deformation temperature. Meanwhile, the Zener-Hollomon parameter is widely used to demonstrate the coupled influence of deformation temperature and strain rate on the hot deformation behaviors [36].

$$
Z=\dot{\varepsilon} \exp \left(\frac{Q}{R T}\right)
$$

According to eq. (1), the strain rate can be expressed as the function of true stress and the deformation temperature, i. e.

$$
\dot{\varepsilon}=A F(\sigma) \exp \left(-\frac{Q}{R T}\right),
$$

where

$$
F(\sigma)=\left\{\begin{array}{cc}
\sigma^{n_{1}} & \alpha \sigma<0.8 \\
\exp (\beta \sigma) & \alpha \sigma>1.2 \\
{[\sinh (\alpha \sigma)]^{n}} & \text { for all } \sigma
\end{array},\right.
$$

where $\dot{\varepsilon}$ represents the strain rate $\left(\mathrm{s}^{-1}\right), \sigma$ means the true stress (MPa), $R$ is the universal gas constant $\left(R=8.31 \mathrm{Jmol}^{-1} \mathrm{~K}^{-1}\right), T$ refers to the deformation temperature $(\mathrm{K})$, and $Q$ is the apparent deformation activation energy $\left(\mathrm{kJmol}^{-1}\right) \cdot n$ implies the stress exponent, $A, \alpha$ and $n_{1}$ are the material constants, where $\alpha=\beta / n_{1}$. Generally $n \neq n_{1}$, although $n=n_{1}$ occurs at a certain $\alpha$.
For the low-level stress $(\alpha \sigma<0.8)$, the strain rate can be obtained by eq. (1):

$$
\dot{\varepsilon}=A_{1} \sigma^{n_{1}} \exp \left(-\frac{Q}{R T}\right) \text {, for } \alpha \sigma<0.8
$$

For the high-level stress $(\alpha \sigma>1.2)$, the strain rate can be expressed as

$$
\dot{\varepsilon}=A_{2} \exp (\beta \sigma) \exp \left(-\frac{Q}{R T}\right), \quad \alpha \sigma>1.2, \alpha=\beta / n_{1},
$$

where material constants $A_{1}$ and $A_{2}$ are independent to the deformation temperatures.

To calculate the above parameters, the true stress-true strain data obtained from isothermal compression experiments with the strain rate ranging from 0.001 to $1 \mathrm{~s}^{-1}$ and deformation temperature ranging from 1,193 to $1,313 \mathrm{~K}$ $\left(920-1,040{ }^{\circ} \mathrm{C}\right)$ are applied.

Logarithmic form of each side of eqs. (4) and (5), gives,

$$
\begin{gathered}
\ln \dot{\varepsilon}=\ln A_{1}+n_{1} \ln \sigma-Q /(R T), \\
\ln \dot{\varepsilon}=\ln A_{2}+\beta \sigma-Q /(R T) .
\end{gathered}
$$

Afterwards, true stresses $\sigma$ and associated strain rates $\dot{\varepsilon}$ at a selected deformation strain of 0.4 are substituted into eqs. (6) and (7). Then $n_{1}$ can be obtained from the slope of $\ln \dot{\varepsilon}-\ln \sigma$, and $\beta$ is identified from the slope of $\ln \dot{\varepsilon}-\sigma$. In order to determine the values of $Q, A$ and $\alpha$, the parameters $n_{1}$ and $\beta$ can be defined as,

$$
n_{1}=\left[\frac{\partial \ln \dot{\varepsilon}}{\partial \ln \sigma}\right]_{T}=\left[\frac{\partial \ln \sigma}{\partial \ln \dot{\varepsilon}}\right]_{T}^{-1},
$$

$$
\beta=\left[\frac{\partial \ln \dot{\varepsilon}}{\partial \sigma}\right]_{T}=\left[\frac{\partial \sigma}{\partial \ln \dot{\varepsilon}}\right]_{T}^{-1} .
$$

Figure 2 shows relationship of true stresses and strain rate at true strain of 0.4 . Then the parameters $n_{1}$ and $\beta$ can be identified from the slops of $\ln \sigma-\ln \dot{\varepsilon}$ and $\sigma-\ln \dot{\varepsilon}$, respectively. Here $n_{1}$ and $\alpha$ are 5.347 and $0.0416 \mathrm{MPa}^{-1}$. For all the stress level, eq. (2) can be written as:

$$
\dot{\varepsilon}=A[\sin h(\alpha \sigma)]^{n} \exp (-Q / R T) .
$$

Taking logarithm of each side of eq. (10) gives 


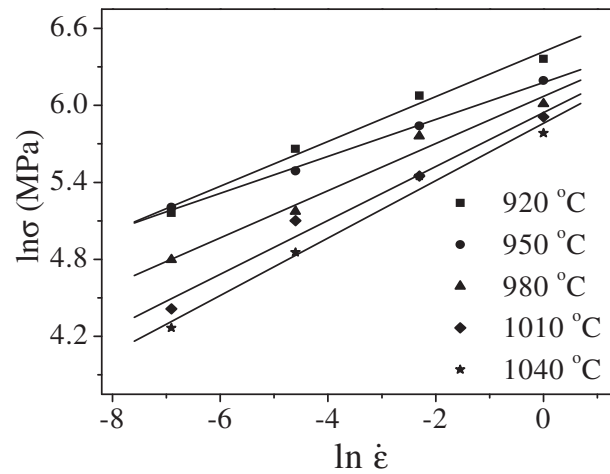

(a)

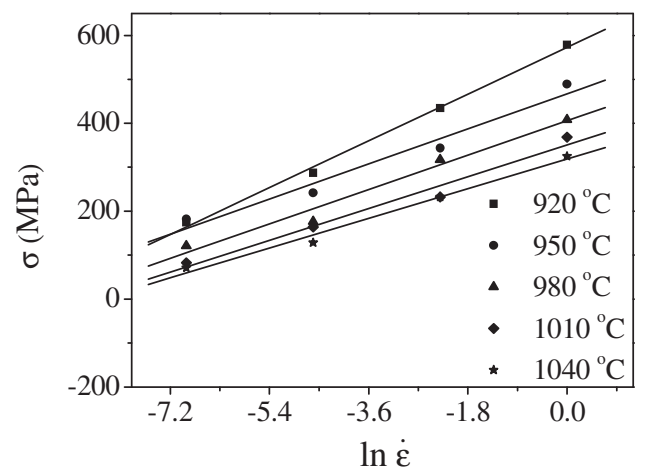

(b)

Figure 2: Relationships between: (a) $\ln \sigma \sim \ln \dot{\varepsilon}$; (b) $\sigma \sim \ln \dot{\varepsilon}$.

$$
\ln \dot{\varepsilon}=\frac{R T \ln A-Q}{R T}+n \ln [\sin h(\alpha \sigma)]
$$

Figure 3a illustrates $\ln [\sinh (\alpha \sigma)]$ and $\ln \dot{\varepsilon}$ plot. Visibly, there is a linear relationship between $\ln [\sinh (\alpha \sigma)]$ and $\ln \dot{\varepsilon}$. Thus, $n$ can be easily determined by eq. (12) as 3.948 .

$$
n=\left[\frac{\partial \ln \dot{\varepsilon}}{\partial \ln [\sinh (\alpha \sigma)]}\right]_{T}=\left[\frac{\partial \ln [\sinh (\alpha \sigma)]}{\partial \ln \dot{\varepsilon}}\right]_{T}^{-1} .
$$

Differentiating eq. (10) gives,

$$
Q=R n\left[\frac{\partial \ln [\sinh (\alpha \sigma)]}{\partial(1 / T)}\right]_{\dot{\varepsilon}}
$$

The value of activation energy $Q$ can be obtained from the slopes of $\ln [\sinh (\alpha \sigma)]-1 / T$ plot (Figure $3 \mathrm{~b}$ ), and $Q$ is identified as $450.977 \mathrm{~kJ} \cdot \mathrm{mol}^{-1}$.

For all the stress level, eq. (1) can be represented as the following,

$$
Z=\dot{\varepsilon} \exp \left(\frac{Q}{R T}\right)=A[\sinh (\alpha \sigma)]^{n}
$$

According to eq. (14), the true stress $(\sigma)$ can be rewritten as a mathematical function with independent variable of Zener-Hollomon. Thus, the proposed constitutive model can be revised as:

$$
\left\{\begin{array}{l}
\sigma=\frac{1}{\alpha} \ln \left\{\left(\frac{Z}{A}\right)^{1 / n}+\left[\left(\frac{Z}{A}\right)^{2 / n}+1\right]^{1 / 2}\right\} . \\
Z=\dot{\varepsilon} \exp \left(\frac{Q}{R T}\right)
\end{array}\right.
$$

The logarithm conversion of each side of eq. (14) can be expressed as,

$$
\ln Z=\ln A+n \ln [\sinh (\alpha \sigma)]
$$

According to measured true stress-strain data, the correlation between $\ln Z$ and $\ln [\sin \mathrm{h}(\alpha \sigma)]$ can be depicted in Figure 4. Thus, $A$ can be estimated as $9.661 \times 10^{16} \mathrm{~s}^{-1}$. Accordingly, $n$ can be re-determined as 3.893 .

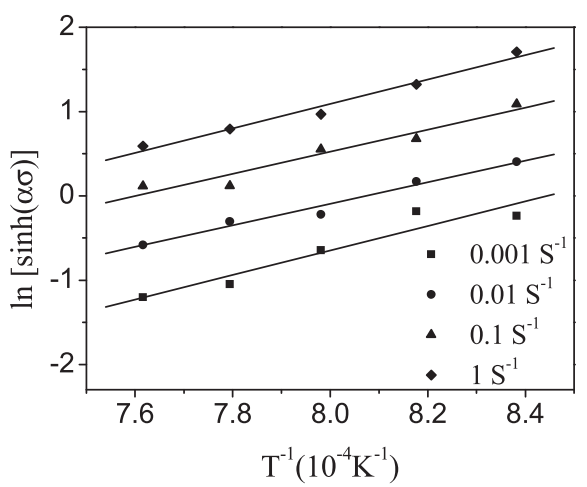

(a)

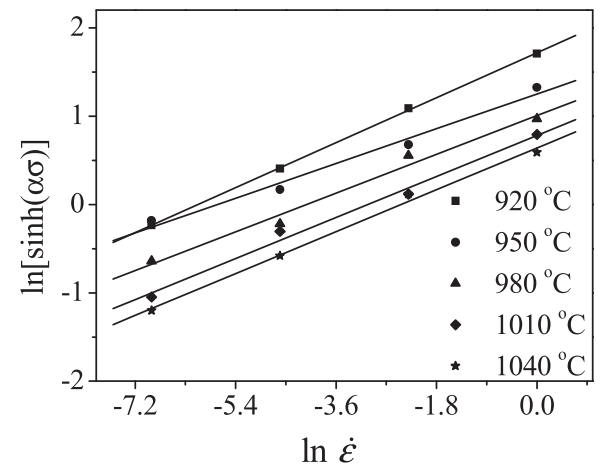

(b)

Figure 3: Relationships between: (a) $\ln [\sin \mathrm{h}(\alpha \sigma)] \sim \ln \dot{\varepsilon}$; (b) $\ln [\sin \mathrm{h}(\alpha \sigma)] \sim T^{-1}$. 


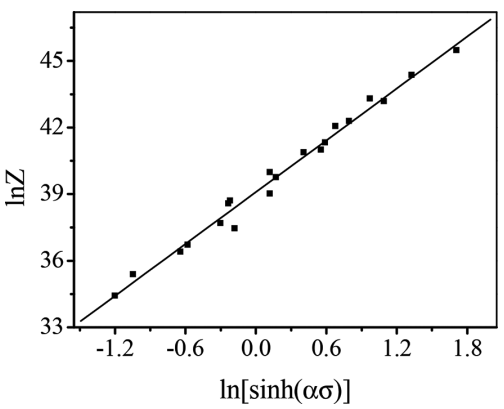

Figure 4: Relationship between $\ln Z$ and $\ln [\sinh (\alpha \sigma)]$.

Summarily, the constitutive equation of Inconel 718 superalloy can be expressed as,

$$
\begin{aligned}
\dot{\varepsilon} & =\mathrm{A}[\sinh (\alpha \sigma)]^{n} \exp \left(\frac{-Q}{R T}\right) \\
& =9.661 \times 10^{16} \times[\sinh (0.00416 \times \sigma)]^{3.893} \exp \left(\frac{-451.977}{R T}\right) .
\end{aligned}
$$

Using the similar procedure, the material constants $(\alpha, n, Q, A)$ can be obtained at different strains. The range of deformation strains is chosen from 0.03 to 0.6 at an interval of 0.038. Then, the relationship between $\alpha, n, Q, \ln A$ and strain for the studied superalloy (Figure 5) can be identified by the fitting method, i.e.

$$
\left\{\begin{array}{l}
\alpha=B_{0}+B_{1} \varepsilon+B_{2} \varepsilon^{2}+B_{3} \varepsilon^{3}+B_{4} \varepsilon^{4}+B_{5} \varepsilon^{5} \\
n=C_{0}+C_{1} \varepsilon+C_{2} \varepsilon^{2}+C_{3} \varepsilon^{3}+C_{4} \varepsilon^{4}+C_{5} \varepsilon^{5} \\
Q=D_{0}+D_{1} \varepsilon+D_{2} \varepsilon^{2}+D_{3} \varepsilon^{3}+D_{4} \varepsilon^{4}+D_{5} \varepsilon^{5} \\
\ln A=E_{0}+E_{1} \varepsilon+E_{2} \varepsilon^{2}+E_{3} \varepsilon^{3}+E_{4} \varepsilon^{4}+E_{5} \varepsilon^{5^{5}}
\end{array}\right.
$$

where the material constants of $\alpha, n, Q, \ln A$ are given in Table 2.

\section{Verification of the developed constitutive equations}

The true stresses of measured and predicted are compared, as shown in Figure 6. Remarkably, there is a satisfied accordance between measured and predicted stress. So, the established constitutive model is reliable to describe the hot deformation behaviors of the studied superalloy. The relative error between the predicted and measured true stresses is counted by eq. (19),

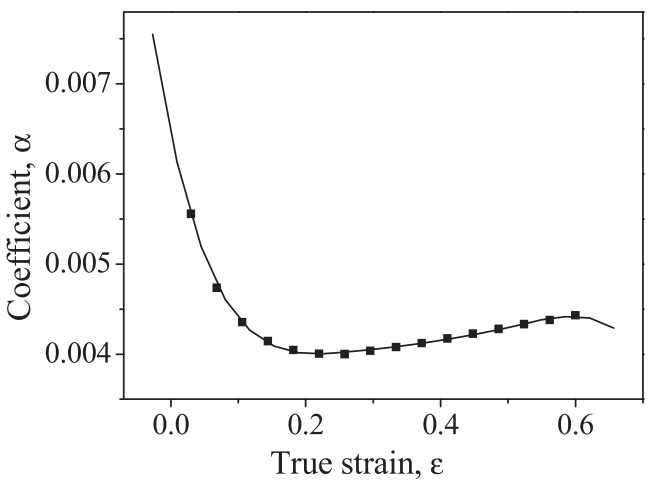

(a)

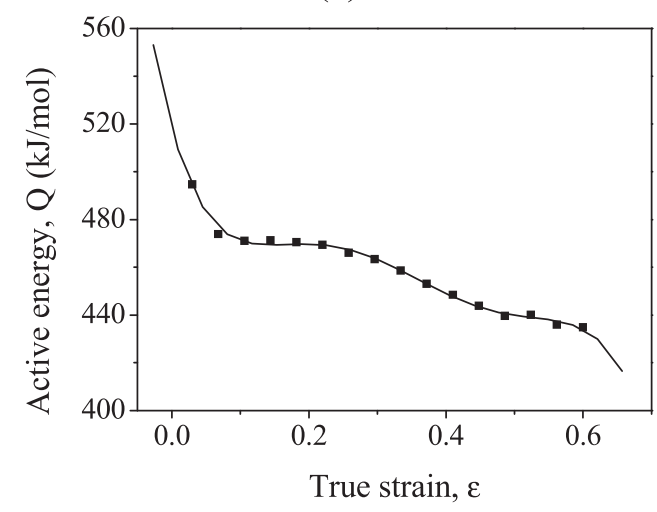

(c)

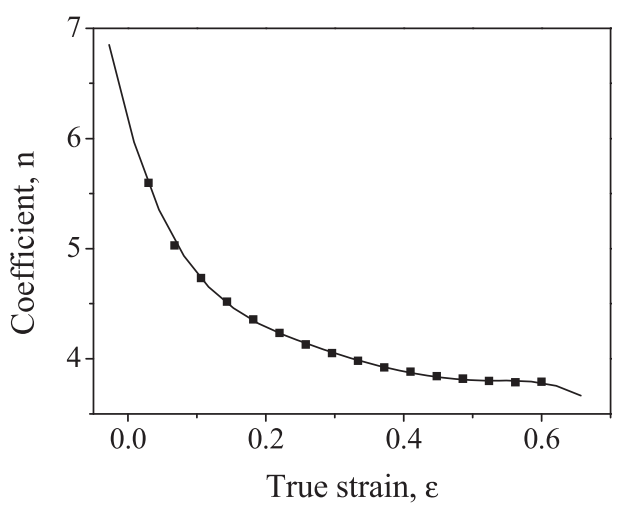

(b)

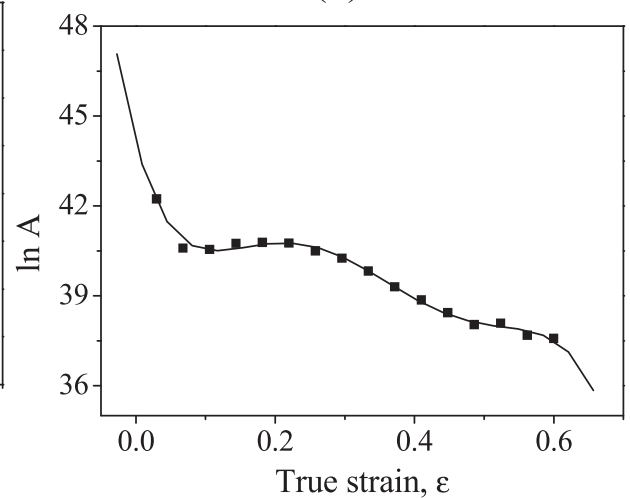

(d)

Figure 5: Relationships between (a) $a$; (b) $n$; (c) $Q$; (d) $\ln A$ and true strain by polynomial fit of Inconel 718 . 
Table 2: The values of $\alpha, n, Q, \ln A$ for the studied superalloy.

\begin{tabular}{lrlllllr}
\hline$\alpha\left(\mathrm{MPa}^{-1}\right)$ & & $n$ & & $Q(\mathrm{~kJ} / \mathrm{mol})$ & \multicolumn{3}{l}{$\ln \boldsymbol{A}\left(\mathbf{s}^{-1}\right)$} \\
\hline $\mathrm{B}_{0}$ & 0.01 & $\mathrm{C}_{0}$ & 6.16 & $\mathrm{D}_{0}$ & 518.10 & $\mathrm{E}_{0}$ & 44.12 \\
$\mathrm{~B}_{1}$ & -0.04 & $\mathrm{C}_{1}$ & -22.34 & $\mathrm{D}_{1}$ & $-1,048.34$ & $\mathrm{E}_{1}$ & -87.09 \\
$\mathrm{~B}_{2}$ & 0.20 & $\mathrm{C}_{2}$ & 111.46 & $\mathrm{D}_{2}$ & $8,302.94$ & $\mathrm{E}_{2}$ & 744.09 \\
$\mathrm{~B}_{3}$ & -0.54 & $\mathrm{C}_{3}$ & -308.90 & $\mathrm{D}_{3}$ & $-29,517.00$ & $\mathrm{E}_{3}$ & $-2,727.12$ \\
$\mathrm{~B}_{4}$ & 0.71 & $\mathrm{C}_{4}$ & 426.90 & $\mathrm{D}_{4}$ & $46,059.40$ & $\mathrm{E}_{4}$ & $4,312.86$ \\
$\mathrm{~B}_{5}$ & -0.37 & $\mathrm{C}_{5}$ & -227.65 & $\mathrm{D}_{5}$ & $-26,205.30$ & $\mathrm{E}_{5}$ & $-2,470.56$ \\
\hline
\end{tabular}

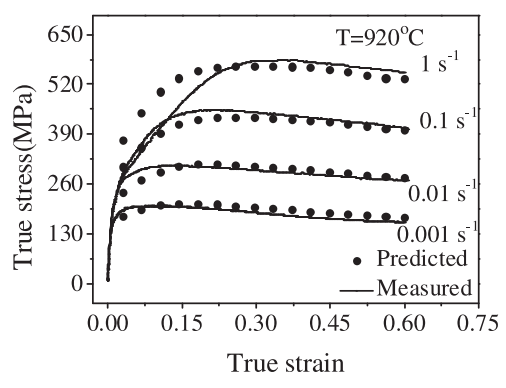

(a)

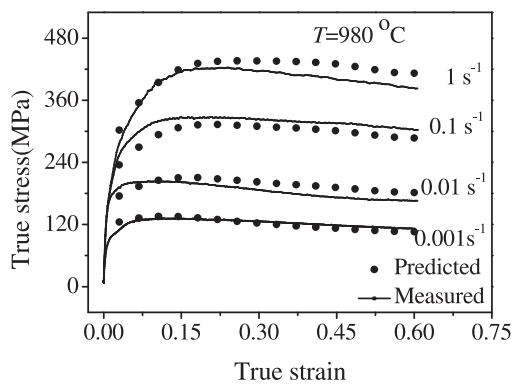

(c)

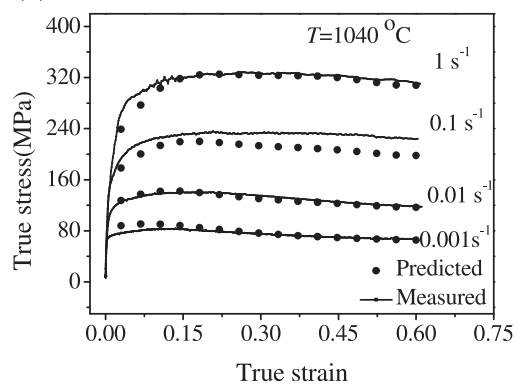

(e)

$$
\text { error }=\frac{\sigma_{P}-\sigma_{M}}{\sigma_{M}} \times 100 \% \text {, }
$$

where $\sigma_{P}$ denotes the predicted stress, and $\sigma_{M}$ means measured true stress. Standard deviation is calculated by eq. (20),

$$
\text { S.D. }=\sqrt{\frac{N \sum x^{2}-\left(\sum x\right)^{2}}{N(N-1)}},
$$

where $N$ is the number of samples, $x$ is the average of relative errors.
Figure 6: Comparisons between predicted and measured true stresses of the studied superalloy at the deformation temperatures of: (a) $920{ }^{\circ} \mathrm{C}$; (b) $950{ }^{\circ} \mathrm{C}$; (c) $980{ }^{\circ} \mathrm{C}$; (d) $1010^{\circ} \mathrm{C}$; (e) $1040{ }^{\circ} \mathrm{C}$

Table 3 exhibits the error evaluating for the established model. It can be seen that the maximum average relative error of estimating the true stress is $2.49 \%$, and the maximum standard deviation of relative errors is $12.48 \%$, which occurs at the relatively low deformation temperatures and high strain rates, such as $920{ }^{\circ} \mathrm{C}$ and $1 \mathrm{~s}^{-1}$. The larger deviations are related to the weak dynamic recovery at high strain rates. The previous investigation [37] indicates that the stacking fault energy is low for the studied superalloy. Accordingly, the mobility of dislocations reduces the mobility of dislocations 
Table 3: Error analysis of predicted $\left(\sigma_{P}\right)$ and measured true stress $\left(\sigma_{M}\right)$.

\begin{tabular}{lrr}
\hline Strain rate $\left(\mathbf{s}^{-1}\right)$ & $\begin{array}{r}\text { Maximum average } \\
\text { relative error (\%) }\end{array}$ & Standard deviation (\%) \\
\hline 0.001 & -0.09 & 9.33 \\
0.01 & -0.29 & 5.99 \\
0.1 & -1.89 & 2.61 \\
1 & 2.49 & 12.48 \\
\hline
\end{tabular}

and the DRV rate is lowered. Particularly, there is no sufficient time for the dislocation climb and cross slip. So, the actual DRV rate is lower than that of the predicted one. Thus, there is a relatively large deviation between the predicted and experimental true stresses at the high strain rates and low deformation temperatures. However, at other tested conditions, the developed constitutive model can give an accurate estimation of the true stress for the studied superalloy. So, it can be applied to the actual hot forming process.

\section{Conclusions}

The deformation characteristics of Inconel 718 superalloy are investigated by hot compression tests at wide ranges of deformation temperature and strain rate. Some remarkable conclusions can be summarized as:

(1) The true stresses are susceptible to the deformation temperature, strain rate and strain. The true stress increases rapidly at the beginning of deformation, which ascribes to the intense work hardening. The true stresses at high deformation temperatures are lower than those at lower deformation temperatures. The dynamic softening induced by DRX is weak at a relatively low deformation temperature.

(2) A strain-compensated Arrhenius-type constitutive equation is developed to predict the flow stress of studied superalloy. In the established model, the material constants $(\alpha, n, Q$ and $A)$ are expressed as the functions of true strain.

(3) A nice agreement between the experimental and predicted true stresses indicates that the developed constitutive equation can reliably describe the hot deformation behavior of the studied superalloy.

Acknowledgements: This work was supported by financial support from the program of China Scholarships Council (Grant No. 201706375019), Natural Science
Foundation of Hunan Province (Grant No. 2017JJ3326), Key Laboratory of Safety Design and Reliability Technology for Engineering Vehicle, College of Hunan Province (Grant No. 2016KF1603), National Postdoctoral Program for Innovative Talents (No. BX201600193), Postdoctoral Science Foundation (No. 2017M612579), Scientific Research Fund of Hunan Province Education Department (No. 17B009), and the scholarship under the State Scholarship Fund managed by the China Scholarship Council (No. 201706375019).

\section{References}

[1] Y.C. Lin and X.M. Chen, Mater. Des., 32 (2011) 1733-1759.

[2] D. Samantaray, S. Mandal and A.K. Bhaduri, Mater. Des., 31 (2010) 981-984.

[3] D.X. Wen, Y.C. Lin and Y. Zhou, Vacuum, 141 (2017) 316-327.

[4] Y.X. Liu, Y.C. Lin and Y. Zhou, Mater. Sci. Eng. A, 691 (2017) 88-99.

[5] Y.Q. Jiang, Y.C. Lin, X.Y. Zhang, C. Chen, Q.W. Wang and G.D. Pang, Vacuum, 156 (2018) 187-197.

[6] Y.C. Lin, J. Huang, H.B. Li and D.D. Chen, Vacuum, 157 (2018) 83-91.

[7] Y.C. Lin, F. Wu, Q.W. Wang, D.D. Chen and S.K. Singh, Vacuum, 151 (2018) 283-293.

[8] D.X. Wen, Y.C. Lin, X.H. Li and S.K. Singh, J. Alloy. Compd., 764 (2018) 1008-1020.

[9] Y.C. Lin, S.C. Luo, L.X. Yin and J. Huang, J. Alloy. Compd., 739 (2018) 590-599.

[10] D.G. He, Y.C. Lin, J. Huang and Y. Tang, Adv. Eng. Mater., 20 (2018) 1800129.

[11] Y.C. Lin, S.C. Luo, X.Y. Jiang, Y. Tang, M.S. Chen and T. Nonferr, Metal Soc., 28 (2018) 592-603.

[12] Y.C. Lin, W.Y. Dong, M. Zhou, D.X. Wen and D.D. Chen, Mater. Sci. Eng. A, 718 (2018) 165-172.

[13] Y.C. Lin, M.S. Chen and J. Zhong, Comput. Mater. Sci., 42 (3) (2008) 470-477.

[14] S. Kumar, D. Samantaray, U. Borah and A.K. Bhaduri, Trans. Indian Inst. Met., 70 (2017) 1857-1867.

[15] G.Z. Quan, J. Liu, A. Mao, B. Liu and J.S. Zhang, High Temp. Mater. Proc., 34 (2015) 643-650.

[16] H.B. Li and Y.L. Feng, High Temp. Mater. Proc., 35 (2016) 55-64.

[17] S. Mandal, V. Rakesh, P.V. Sivaprasad, S. Venugopal and K.V. Kasiviswanathan, Mater. Sci. Eng. A, 500 (2009) 114-121.

[18] D.G. He, Y.C. Lin, J. Chen, D.D. Chen, J. Huang, Y. Tang and M.S. Chen, Mater. Des., 154 (2018) 51-62.

[19] Y.C. Lin, J. Li, M.S. Chen, Y.X. Liu and Y.J. Liang, Neural Comput. Appl., 29 (2018) 1015-1023.

[20] L. Li and L. Wang, High Temp. Mater. Proc., 37 (2018) 411-424.

[21] D.D. Chen, Y.C. Lin, Y. Zhou, M.S. Chen and D.X. Wen, J. Alloy. Compd., 708 (2017) 938-946.

[22] M.S. Chen, Y.C. Lin, K.K. Li and J. Chen, Appl. Phys. A, 122 (2016) 869.

[23] Y.X. Liu and Y.C. Lin, High Temp. Mater. Proc. (2018). doi: 10.1515/htmp-2017-0096. 
[24] D.G. He, Y.C. Lin, X.Y. Jiang, L.X. Yin, L.H. Wang and Q. Wu, Mater. Des., 156 (2018) 262-271.

[25] Y.C. Lin, H. Yang, Y.C. Xin and C.Z. Li, Mater. Charact., 144 (2018) 9-21.

[26] Y.C. Lin, X.Y. Jiang, S.C. Luo and D.G. He, Mater. Des., 139 (2018) 16-24.

[27] Y.C. Lin, M. He, M. Zhou, D.X. Wen and J. Chen, J. Mater. Eng. Perform., 24 (2015) 3527-3538.

[28] M. Azarbarmas, M. Aghaie-Khafri, J.M. Cabrera and J. Calvo, Mater. Des., 94 (2016) 28-38.

[29] Y.C. Lin, D.X. Wen, J. Deng, G. Liu and J. Chen, Mater. Des., 59 (2014) 115-123.

[30] X.M. Chen, Y.C. Lin, M.S. Chen, H.B. Li, D.X. Wen, J.L. Zhang and M. He, Mater. Des., 77 (2015) 41-49.
[31] Y.C. Lin, D.G. He, M.S. Chen, X.M. Chen and C.Y. Zhao, Mater. Des., 97 (2016) 13-24.

[32] Y.C. Lin, F.Q. Nong, X.M. Chen, D.D. Chen and M.S. Chen, Vacuum, 137 (2017) 104-114.

[33] X.M. Chen, Y.C. Lin, D.X. Wen, J.L. Zhang and M. He, Mater. Des., 57 (2014) 568-577.

[34] Y.H. Liu, Y.Q. Ning, X.M. Yang, Z.K. Yao and H.Z. Guo, Mater. Des., 95 (2016) 669-676.

[35] S.Z. Najafi, A. Momeni, H.R. Jafarian and S. Ghadar, Mater. Charact., 132 (2017) 437-447.

[36] C. Zener and J.H. Hollomon, J. Appl. Phys., 15 (1944) 22-32.

[37] Y.C. Lin, X.M. Chen, D.X. Wen and M.S. Chen, Comput. Mater. Sci., 83 (2014) 282-289. 